\title{
La confrontación de ontología y epistemología en el pensamiento gadameriano
}

Ramón Bárcenas

Universidad de Guanajuato

Resumen

Heidegger formula una de las tesis filosóficas más radicales del siglo XX: la distinción puntual entre los estudios sobre lo óntico y los análisis ontológicos. Este planteamiento da lugar a la escisión fundamental entre la epistemología, cuyo tema es el ser-objeto, y la hermenéutica ontológica, que analiza el carácter de ser del existir. Uno de los intentos más notables por poner en juego estas dos posturas tan distanciadas se encuentra en la filosofía gadameriana, la cual se caracteriza por sostener que la comprensión verdadera acontece bajo la forma del diálogo. Este trabajo revisa si el esfuerzo gadameriano por aproximar la epistemología a la ontología tiene lugar bajo la forma del diálogo hermenéutico.

Palabras clave: ontología, hermenéutica, comprender, diálogo, epistemología. 


\section{Abstract}

Heidegger formulates one of the most radical theses in the philosophy of the twenty century: the distinction between the studies on specific entities and those on Being itself (ontology). This thesis shows the essential difference between epistemology and ontological hermeneutics, since the first deals with objectivity, while the second worries about Being. Gadamer's philosophy, which holds that true understanding takes place dialogically, represents one of the most important efforts to draw near these two divorced positions. This paper analyzes in what sense Gadamer's attempt to confront ontology with epistemology takes place dialogically.

Keywords: Ontology, hermeneutics, understanding, dialogue, epistemology.

G n el verano de 1923 Heidegger impartió en Friburgo una serie de lecciones bajo el título de "Ontología: Hermenéutica de la facticidad". Posteriormente, estas lecciones fueron publicadas en un libro homónimo. En este texto se ofrece una caracterización ontológica de la hermenéutica. Aquí el término "hermenéutica" no refiere más a un arte o una doctrina del comprender. El vocablo remite, más bien, a una cierta sistematicidad en el modo de plantear, acceder y explicar la facticidad. La facticidad, a su vez, designa "el carácter de ser de 'nuestro' existir 'propio”" (Heidegger, 2008: 25). De acuerdo con esto, la hermenéutica tiene la labor de hacer accesible al existir su particular modo de ser. Lo que se busca es que el existir, o ser ahí (Dasein), se ponga en marcha hacia sí mismo, que "despierte" para consigo mismo. Se trata de que al existir le sea patente su propio carácter de ser, consistente en ser hermenéutico.

La hermenéutica tiene la labor de hacer al existir mismo propio de cada momento accesible en su carácter de ser al existir mismo, de 
comunicárselo, de tratar de aclarar esa alienación de sí mismo de que está afectado el existir. En la hermenéutica se configura para el existir mismo una posibilidad de llegar a entenderse y de ser ese entender (Heidegger, 2008: 33).

Este entender (Verstehen), por supuesto, no se logra a través de ningún comportamiento subjetivo como la reflexión; no tiene relación con algún proceso cognoscitivo. El entender del que aquí se habla constituye una determinación fundamental del ser del existir. Que el comprender determina el carácter de ser del existir quiere decir que se concibe en un plano estrictamente ontológico. El comprender es un existenciario (Existenzial), y éste es el nombre dado a las explicaciones surgidas del análisis ontológico del ser ahí. En este sentido, la hermenéutica de la facticidad se caracteriza por su orientación ontológica y no tiene que ver con una teoría de la interpretación, la cual remite a una metodología del comprender. Esto es precisamente lo que Dilthey entiende por hermenéutica: "A esta teoría de la preceptiva del comprender manifestaciones de la vida fijadas por escrito la llamamos hermenéutica [proposición 4b]" (Dilthey, 2000: 85). La hermenéutica se plantea aquí en un plano estrictamente epistemológico, en la medida en que su interés se centra en la posibilidad de fundar un saber objetivo de la realidad espiritual. El contenido temático de la hermenéutica diltheyana es la vida misma, pero sólo en la medida en que ella deviene objeto de conocimiento.

Heidegger rechaza la concepción epistemológica de la hermenéutica porque ésta se sitúa en un nivel óntico y no ontológico. El análisis ontológico busca caracterizar el ámbito de lo fundamental. En este sentido, la hermenéutica de la facticidad busca explicitar la estructura ontológica de lo originario: el existir mismo en cuanto tal. En cambio, para la epistemología la esfera de lo primordial está representada en el esquema sujeto-objeto. Presupone que lo 
primario es la existencia de "yoes" (sujetos) que se contraponen a "no-yoes" (objetos). Así, una teoría del conocimiento se articula sobre una base o bien "subjetiva" o bien "objetiva”, según se opte por uno de los dos extremos. Por ejemplo, el cogito se constituye como el fundamento absoluto de la filosofía cartesiana. Lo que pone de manifiesto el carácter "sustancial" del "yo pienso" es la rigurosidad del proceder de la duda metódica. El cogito se revela así en cuanto ente sustancial, entendiendo por esto lo permanente, es decir, aquello que subsiste por sí mismo. Descartes lo define de la siguiente manera: "Cuando concebimos la substancia, solamente concebimos una cosa que existe en forma tal que no tiene necesidad sino de sí misma para existir" (Descartes, 1995: 52).

Pues bien, el problema con la perspectiva epistemológica es que asume como originario lo que en realidad es una cuestión derivada. Para Heidegger la investigación epistemológica atañe, en todo caso, sólo a una forma específica de ser del existir. Sin embargo, dicha forma de ser no es ni la más fundamental ni mucho menos la única posible. Esto significa que el modo originario de ser del existir no se reduce a un sujeto del conocimiento, es decir, no es primordialmente un "yo" (sujeto) que se contrapone a un "no-yo" (objeto). "El existir no es [...] algo que esté compuesto de vivencias, ni mucho menos es el sujeto (yo) que está frente al objeto (no yo)" (Heidegger, 2008: 68). El ser ahí es, ciertamente, un ente, pero un ente cuya peculiaridad óntica es ser ontológico. En este sentido, el ser ahí es "esencialmente" existencia. Que el ser ahí es existencia significa que no es pura presencia (sustancia), sino que es un ser, más aún, un poder ser. La existencia, en cuanto poder ser, implica apertura en el sentido de un ser proyectado en el mundo. Existir, por lo tanto, es ser en el mundo (in-der-Welt-sein). Lo originario, lo primario, es este ser en el mundo y no la relación epistemológica de sujeto-objeto. Antes de ser un sujeto del conocimiento, se es un ser arrojado en el mundo, en el "ahí". En este sentido, el comportamiento cognoscitivo no puede 
dar cuenta del modo inicial de relacionarnos con el mundo. Por el contrario, el mismo conocimiento del mundo (Welterkennen) es sólo una forma de ser derivada de la estructura fundamental de ser en el mundo. En palabras de Heidegger: "ni el conocimiento crea $a b$ initio un commercium del sujeto con un mundo, ni este commercium surge de una acción del mundo sobre un sujeto. El conocimiento es un modo del 'ser ahí' fundado en el 'ser en el mundo"' (Heidegger, 2007: 75).

De lo anterior se sigue que el modo en que el ser ahí es en el mundo no se caracteriza por el comportamiento teorético, sino por el fundamental "curarse de". Las cosas que inmediatamente hacen frente en el mundo cotidiano no se ofrecen cual meros objetos materiales, sino que se presentan, sobre todo, como entes con una función. La mesa que encontramos en una habitación no se ofrece primariamente como un mero ente espacial con determinadas propiedades físicas: color, peso, altitud, etc. La mesa es, sobre todo, esto: la mesa en la que uno se sienta a escribir, la mesa que se utiliza "para" trabajar; es un ente que sirve "para algo", un algo útil. "La mesa en sí misma aparece de primeras así; no es que se adjudique ese rasgo de ser 'para algo' de resultas de una comparación con algo distinto de lo que ella es" (Heidegger, 2008: 115). La contemplación teorética no es, por lo tanto, el modo primario de relacionarnos con las cosas, sino el curarse de que manipula. Sólo cuando se pasa por alto este ocuparse de es que las cosas se muestran cual meros objetos susceptibles de ser conocidos. En consecuencia, el ser de la mesa, su utilidad, no es algo que se ofrezca a una mirada desinteresada, sino a un manipular efectivo de tal ente.

En el andar por el mundo curándose de cosas al manejarlas, el ser ahí las comprende "como" útiles; es decir, los entes le hacen frente como mesa, puerta, etc. Es inherente al ser del ser ahí el que las cosas intramundanas se le presenten en la modalidad de "algo como algo". Al hacer uso de la puerta, haciendo girar el pestillo, se comprende la 
puerta como tal, sin que esto se tenga que pensar o expresar verbalmente. Este entender primario es pre-teórico, ante-predicativo, y se revela en el uso mismo de los útiles, de forma tal que no tiene nada que ver con un proceso cognoscitivo. El comprender del que aquí se habla remite al carácter de ser del ser ahí; mienta una capacidad originaria del existir humano consistente en un poder ser en el mundo, en un saber arreglárselas en él. Por esta razón, se dice que una persona no comprende una cosa cuando no sabe cómo "prenderla" y hacer uso de ella. El comprender ante-predicativo es inherente al trato ocupado con las cosas porque constituye el modo en que el ser ahí es en el mundo. Este comprender como (als), también denominado "como hermenéutico", es previo a toda interpretación filológica o científica. Antes de que sea posible la interpretación de un texto, es necesario haberlo comprendido ya como tal, esto es, como texto. De esta forma el "como hermenéutico" funge como condición de posibilidad del "como apofántico".

El "entender como" se configura, a su vez, sobre tres elementos fundamentales: el "tener previo" (Vorhabe), el "ver previo" (Vorsicht) y el "concebir previo" (Vorgriff). Así, la comprensión implícita en la manipulación efectiva de un útil, presupone el tener dicho útil, el verlo en relación con otros útiles (plexo de referencias) y el concebirlo de una manera determinada. "La interpretación de algo como algo tiene sus esenciales fundamentos en el 'tener', el 'ver' y el 'concebir' 'previos'. Una interpretación jamás es una aprehensión de algo dado llevada a cabo sin presupuestos" (Heidegger, 2007: 168). De acuerdo con esto, toda interpretación se configura sobre una pre-comprensión, de manera tal que no es posible desarrollar una investigación partiendo de una base neutral. Si la interpretación se ejerce sobre una pre-comprensión, entonces esto implica moverse en un círculo, pues se presupone justamente lo que requiere ser explicado. Sin embargo, esta circularidad no mienta una forma de conocer sino que pertenece con toda originalidad a 
la estructura fundamental del comprender. "Este círculo del comprender no es un círculo en que se movería una cierta forma de conocimiento, sino que es la expresión de la existenciaria estructura del 'previo' peculiar al 'ser ahí' mismo" (Heidegger, 2007: 171). El círculo hermenéutico no es entonces ningún error lógico o epistemológico que debiera evitarse, sino que revela la originaria estructura de anticipación propia de la experiencia humana.

Las consideraciones anteriores buscan poner de manifiesto la siguiente cuestión primordial para este trabajo. Lo que hasta aquí se ha enfatizado es la diferencia sustancial entre hermenéutica ontológica y epistemología. De acuerdo con Heidegger, la hermenéutica busca caracterizar lo originario, lo fundamental, y en este sentido es ontológica. Por esta razón, su tarea consiste en hacer patente al existir su peculiar modo de ser. La epistemología, en cambio, se centra en mostrar el modo en que el sujeto aprehende el objeto del conocimiento. En este sentido, la investigación epistemológica es de carácter óntico, pues su tema de estudio es el ser-objeto, la objetividad. Esta distinción entre lo óntico y lo ontológico nos conduce a una separación radical entre epistemología y hermenéutica, en el sentido en que ambas pertenecen a órdenes diferentes: mientras que la hermenéutica trata de lo originario (el modo de ser del existir), la epistemología versa sobre cuestiones derivadas (el ser-objeto). Esto, a su vez, explica la tesis heideggeriana de que el conocimiento del mundo es sólo posible en cuanto modo de ser derivado de la estructura fundamental de ser en el mundo. A este respecto se ha señalado que el "como hermenéutico" es condición de posibilidad del "como apofántico". En este planteamiento la epistemología se encuentra, en el mejor de los casos, subordinada a la ontología.

Pero si bien es cierto que el esfuerzo heideggeriano por acceder y explicitar lo originario ha puesto de manifiesto la prioridad fundamental de lo ontológico para toda constitución de orden óntico, también es verdad que este autor no mostró el modo específico 
en que, por ejemplo, el "como hermenéutico" determina el "como apofántico". Dicho en otros términos, si bien Heidegger ha realizado el movimiento de remontarse hasta lo originario, exponiendo así la preeminencia de los principios ontológicos por sobre las cuestiones ónticas, lo que no realizó fue el movimiento de retorno, de lo originario a lo derivado, que exhibiría en qué sentido y hasta qué punto los descubrimientos de la hermenéutica ontológica condicionarían las cuestiones epistemológicas. Ofrecer una respuesta a este punto es importante por varias razones. Por un lado, en el trayecto de retorno se verificaría de manera efectiva la pretensión heideggeriana de que las problemáticas epistemológicas y científicas son cuestiones derivadas. Esto permitiría exhibir concretamente de qué manera los principios de la ontología fundamental determinan la constitución de las ciencias humanas. Por otro, se lograría un acercamiento, un tipo de comunicación entre la ontología y las cuestiones científicas; lo cual es deseable, pues, como advierte Ricoeur, "una filosofía que corta el diálogo con las ciencias no se dirige más que a sí misma” (Ricoeur, 2002: 89). En consecuencia, es indispensable el trayecto de retorno desde la ontología fundamental hacia las interrogantes de corte epistemológico.

Gadamer asumió como propia esta tarea y efectúo el trayecto de vuelta desde los principios ontológicos hacia las cuestiones ónticas en su obra principal Verdad y método. En este movimiento de retorno intenta mostrar en qué sentido los descubrimientos de la hermenéutica ontológica posibilitan una mejor comprensión de la naturaleza de la verdad y de las ciencias del espíritu que la planteada por la concepción metodológica. El título mismo de la obra revela una puesta en juego entre ontología y epistemología, esto es, entre la noción heideggeriana de verdad y la concepción diltheyana de método. Ahora bien, existen al menos dos razones importantes para suponer que la aproximación entre estas dos vertientes tendría lugar de manera dialógica. En primera instancia, el título de su 
obra, Verdad y método, anuncia un posible diálogo entre la hermenéutica ontológica y la epistemología. La partícula conjuntiva del título subraya la idea de una aproximación, más aún, de una posible conciliación entre ambas posturas. En segundo lugar, Gadamer es el autor de una hermenéutica filosófica para la cual el verdadero comprender acontece bajo la forma del diálogo. Evidentemente, el diálogo no debe confundirse con el monólogo disfrazado en el que se ignora la opinión del otro y se impone obstinadamente el propio punto de vista; tampoco tiene la estructura de la refutación erística, en la que a cada argumento presentado se opone un contraargumento, y cuyo propósito final es rebatir, a como dé lugar, la posición del interlocutor. El diálogo hermenéutico, al igual que la dialéctica platónica, tiene la forma de una conversación, en la cual participa una pluralidad de voces que buscan alcanzar algo en común; a saber: un entendimiento sobre aquello de que se habla. Lo que caracteriza al diálogo es precisamente ese esfuerzo conjunto por llegar a un acuerdo sobre lo deliberado. Lo importante aquí no es vencer a toda costa en la argumentación, sino lograr penetrar conjuntamente en el sentido de lo tratado.

Puesto que dialogar es un acontecer discursivo en el que participan dos o más voces, se sigue que la realización del diálogo hermenéutico precisa de una actitud de apertura al decir de los demás, esto es, de prestar atención a otros modos potencialmente más adecuados de concebir las cosas. En este sentido, la posibilidad de atender a los demás presupone admitir la existencia y validez de perspectivas distintas de la propia, es decir, supone el reconocimiento del otro. El reconocimiento de la alteridad posibilita, a su vez, la adquisición de horizontes, al menos, en la medida en que nos vemos comprometidos a ver más allá del propio punto de vista. Ahora bien, la noción misma de "horizonte" remite a lo abierto, a la condición misma de apertura: "tener horizontes significa no estar limitado a lo más cercano sino poder ver por encima de ello" 
(Gadamer, 2001: 373). Por otro lado, Gadamer reiteró en entrevistas realizadas hacia el final de su vida que el alma de su hermenéutica consiste en la admisión de que el otro puede tener razón (Grondin, 2003: 34). El reconocimiento de que el otro puede estar en lo correcto se correlaciona con el darse cuenta de que el propio punto de vista es falible y limitado. La toma de conciencia de que se puede estar equivocado constituye una actitud de humildad en concordancia con la docta ignorancia socrática.

En este punto cabe preguntar: ¿el modo en que Gadamer busca aproximar la ontológica y la epistemología tiene la forma del diálogo hermenéutico?; ¿busca su obra conciliar la actitud de verdad (ontología) con la conciencia metodológica (epistemología), de forma tal que surja algo en común?; ¡la postura gadameriana hacia el modelo metodológico se caracteriza por ser una actitud de apertura, de escucha? El modo en que Gadamer pone en relación estas posturas no responde a la estructura del diálogo hermenéutico, sino más bien a la de una confrontación. Verdad y método efectivamente contrapone ambas posturas, pero no lo hace con la intención de conciliarlas. Por el contrario, lo que su obra busca es hacer valer la prioridad del planteamiento ontológico por sobre la postura epistemológica; y para lograr esto debe desarticular la supuesta preeminencia y validez universal del método científico. El asunto es que para Gadamer el problema de la verdad -es decir, la experiencia humana de la verdad-sobrepasa con mucho los alcances explicativos de la concepción metodológica (epistemología). Como es sabido, la concepción metodológica sostiene que la manera correcta de acceder al conocimiento es mediante la aplicación del método científico. En este sentido se suele afirmar que una disciplina es "científica" en la medida en que su modo de investigación se rige por tal método. El problema con este modelo es que termina por ofrecernos una imagen distorsionada de la naturaleza de la verdad y de las ciencias humanas. Dicho en otros términos, 
el paradigma metodológico conlleva una drástica reducción de la experiencia humana de la verdad, pues pasa por alto todo aquello que no es explicable en términos epistemológicos.

Las limitaciones de tal paradigma se revelan de manera concreta en su incapacidad para dar cuenta de ciertas formas de la experiencia humana en que se expresa un saber. Las obras de arte, las tradiciones históricas y los discursos filosóficos constituyen formas de verdad que rebasan los alcances del método científico (Gadamer, 2001: 24-5). Por ejemplo, la experiencia del pensar filosófico y la verdad de las obras de arte no dependen de la observancia de algún principio metodológico. En este sentido, no hay reglas que faciliten un pronto filosofar o la rápida comprensión de una obra de arte. La participación del sentido de las producciones artísticas y del saber filosófico demanda otra cosa que meras instancias prescriptivas; precisa trabajo, experiencia y, sobre todo, formación. El problema, según Gadamer, es que el predominio del paradigma metodológico ha terminado por cerrar el acceso a la verdad que se comunica en el arte, las tradiciones históricas y los discursos filosóficos. Por este motivo, la relación que Gadamer establece con la conciencia metodológica no puede ser de carácter dialógico (conciliador), sino crítico (deconstructivo). En este sentido, su pensamiento busca desarticular el encubrimiento en que ha devenido la supuesta universalidad y validez del método científico, con la finalidad de rehabilitar tales formas fundamentales de verdad. Estas experiencias de la verdad son recuperadas en cada una de las tres partes en que se organiza Verdad y método.

Uno de los puntos clave de la deconstrucción del modelo metodológico se encuentra en el debate que Gadamer entabla con la interpretación moderna del prejuicio. Para la Modernidad los prejuicios son meros juicios sin fundamento porque carecen de una justificación última en un criterio racional. El prejuicio de autoridad, por ejemplo, proviene de la incapacidad de emplear la propia 
razón, al adoptar una actitud acrítica ante el decir de la tradición. Para el pensador moderno, la única fuente de autoridad proviene, en todo caso, de la propia razón y no de alguna forma de tradición. Esta idea se expresa en el lema kantiano: “¡Sapere aude! ¡Ten el valor de servirte de tu propia razón!” (Kant, 1994: 25). Esta frase es un llamado a emanciparse del peso de los tutores y de toda figura de autoridad que pretenda usurpar el lugar de la razón. Una implicación de este modo de concebir el prejuicio es que las tradiciones son vistas como fuente de error, esto es, son despojadas de toda posibilidad de transmitir un saber. Por lo tanto, la rehabilitación de la tradición como posible experiencia de verdad precisa de una refutación de esta concepción negativa de prejuicio. Gadamer formula tres argumentos que buscan lograr este fin. El primero de ellos, parte de un análisis filológico que revela que no hay nada en el vocablo "prejuicio" que conlleve necesariamente la idea de “juicio sin fundamento". Prejuicio quiere decir 'juicio previo', cuyo valor de verdad requiere ser constatado. Así, es inherente a todo presupuesto el que pueda devenir en un juicio, esto es, que puede ser valorado de manera positiva. El segundo argumento defiende la idea de que también hay presupuestos legítimos que conducen a la verdad. En relación a esto, se subraya que no todo el decir de las figuras de autoridad es arbitrario. Por ejemplo, el asentimiento al decir de los expertos se funda en el re-conocimiento de que ellos saben más que el resto sobre un tema en cuestión. Por otro lado, las tradiciones históricas, como es el caso de lo clásico, remiten a la conservación y transmisión de aquellas prácticas y realidades que se han legitimado con el paso del tiempo. De esta manera, atender la voz de la tradición también se funda en un acto de la razón, pues remite a aquellas verdades que se han afirmado y acreditado. En el tercero, Gadamer lleva a cabo una rehabilitación hermenéutica del prejuicio al ver expresado en éste la estructura fundamental de la pre-comprensión. Esto significa que los presupuestos, lejos de ser 
fuente de error, se constituyen en condición de posibilidad de la interpretación misma. En este sentido, todo proyecto de interpretación "empieza siempre con conceptos previos que tendrán que ser sustituidos progresivamente por otros más adecuados" (Gadamer, 2001: 333). La preeminencia ontológica de la pre-comprensión exhibe el sinsentido del criterio metodológico de objetividad, pues es imposible dar cabal cumplimiento a este tipo de exigencia. La rehabilitación hermenéutica del prejuicio conlleva la desarticulación del modelo metodológico, en la medida en que se muestra que la propia conciencia del investigador se encuentra condicionada por preconcepciones.

Lo anterior muestra que el prejuicio, en cuanto condicionante de la interpretación, define el posicionamiento desde el cual se formula toda investigación (científica o no). En este sentido, configuran nuestra propia situación hermenéutica, esto es, delimitan los alcances de nuestra perspectiva. Por esta razón, la hermenéutica gadameriana sostiene que nuestros prejuicios, más que nuestros juicios, configuran la realidad histórica de nuestro ser. Esto último significa que no sólo los acontecimientos son de carácter histórico, sino que nosotros mismos estamos sujetos al devenir de la Historia. En este sentido, la propia conciencia del investigador se encuentra determinada por el acontecer histórico. Por este motivo se enfatiza que: "no es la historia la que nos pertenece, sino que somos nosotros los que pertenecemos a ella" (Gadamer, 2001: 344). Frente al ideal metódico y reflexivo que persigue un punto de partida incondicionado y objetivo, la hermenéutica gadameriana antepone la tesis de la historicidad de la propia conciencia científica. Se trata aquí de mostrar que hay algo que precede y posibilita la propia conciencia metodológica; se trata de la recuperación del sentido de pertenencia a las tradiciones que nos anteceden y sustentan. En palabras de Ricoeur: "Por provocante - por no decir provocador- que sea este alegato, tiene que ver con la reconquista de la dimensión histórica por sobre el momento reflexi- 
vo. La historia me precede y adelanta mi reflexión" (Ricoeur, 2002: 92). La tesis de la historicidad de la conciencia tiene consecuencias fundamentales para la teoría del conocimiento: muestra que el conocedor (sujeto) y lo conocido (objeto) no se ofrecen originariamente como meros entes subsistentes, sino que son seres que se constituyen históricamente, es decir, "tienen el modo de ser de la historicidad" (Gadamer, 2000: 76).

El reconocimiento de la historicidad del sujeto entraña saber que no podemos abordar el pasado de manera objetiva porque no podemos sustraernos de la acción de la Historia. Las tradiciones históricas son fundamentalmente acontecer que, en cuanto tal, ejercen su acción, incluso, ahí donde menos conscientes somos de su poder. Por esta razón, a la conciencia histórica se le contrapone una toma de conciencia más adecuada: la conciencia de la historia efectual. Se trata del reconocimiento de que todo, incluyendo la misma conciencia metodológica, se encuentra bajo la acción de la Historia, y de que tal eficacia histórica no es del todo evidente, es decir, no es susceptible de una transparencia plena. Pero esta imposibilidad de hacer plenamente consciente la eficacia histórica no se deriva de alguna falta por parte de nuestro entendimiento, sino que tiene relación con el hecho de que nuestra condición de ser histórico no se reduce ni se agota bajo la perspectiva epistemológica. La conciencia de la historia efectual nos enseña que la razón humana no puede autodeterminarse a través de ciertos recursos metodológicos, pues esto implica pasar por alto la finitud constitutiva del ser hombre. La condición de finitud revela que es inherente al ser humano el encontrarse limitado de varias maneras (por ejemplo, tener limitaciones en cuanto a recursos temporales, cognitivos, etc.). Una de estas formas, precisamente, remite al modo en que los procesos cognitivos se encuentran determinados por la situación hermenéutica desde la que tienen lugar. 


\section{Bibliografía}

Aguilar Rivero, Mariflor, 2005, Diálogo y alteridad. Trazos de la hermenéutica de Gadamer, México, unam (Colección Paideia).

Descartes, Rene, 1995, Los principios de la filosofia, Barcelona, Alianza Editorial.

Dilthey, Wilhelm, 2000, Dos escritos sobre hermenéutica, Madrid, Ediciones Istmo.

Gadamer, Hans-Georg, 2003, Los caminos de Heidegger, Barcelona, Herder Editorial.

, 2002, Verdad y método II, Salamanca, Ediciones Sígueme (Colección Hermeneia).

, 2001, Verdad y método, Salamanca, Ediciones Sígueme (Colección Hermeneia).

,2000, El problema de la conciencia histórica, Madrid, Editorial Tecnos.

Grondin, Jean, 2003, Introducción a Gadamer, Barcelona, Herder Editorial.

Heidegger, Martín, 2008, Ontologia: Hermenéutica de la facticidad, Madrid, Alianza Editorial. , 2007, El ser y el tiempo, México, Fondo de Cultura Económica.

Kant, Emmanuel, 1994, Filosofía de la historia, México, Fondo de Cultura Económica.

Ricoeur, Paul, 2002, Del texto a la acción, ensayos hermenéuticos II, México, Fondo de Cultura Económica. 